\title{
Ligation-Mediated PCR: Robotic Liquid Handling for DNA Damage and Repair
}

BioTechniques 33:1090-1097 (November 2002)

\section{S.-M. Dai, T.R. O'Connor, G.P. Holmquist, A.D. Riggs, and S.D. Flanagan Beckman Research Institute of the City of Hope National Medical Center, Duarte, CA, USA}

\footnotetext{
ABSTRACT

The investigation of in vivo DNA repair in mammalian cells at nucleotide resolution requires the quantification of break frequencies less than one per kilobase. By optimizing several parameters of the ligation-mediated PCR technique, we find that the required sensitivity can be achieved. We also report details of a one-day procedure that can be performed either with or without a robotic liquid handling workstation. The use of near-infrared fluorescent-labeled primers with detection by a LI-COR ${ }^{\circledR}$ DNA sequencer provides for safe, nonradioactive detection, similar in sensitivity to the use of ${ }^{32} P$-labeled primers but with the additional advantage that high-quality digitized data are obtained directly. Multiplexing can be performed; that is, more than one sequence can be analyzed in a single reaction, and multiple reactions can be processed robotically. Primer sets for exons 5-8 of the tumor suppressor gene, p53, were designed for simultaneous thermal cycling. The improved procedure with infrared detection was used to monitor low-frequency damage $(<1$ break/ $k b)$ and/or repair of $U V B$, $U V C$, and chemical methylation. Quantitative data on the linearity of response and reproducibility are described. The coefficient of variation for technical replicates was typically 10\%. The methods described here will permit high sample throughput for the detection of DNA damage and repair as well as in vivo protein footprints.
}

\section{INTRODUCTION}

The ligation-mediated PCR (LMPCR) technique was originally developed as a footprinting technique for determining, at nucleotide-level resolution, the in vivo location of proteins on the DNA in mammalian cells $(15,19)$. Subsequently, LMPCR was adapted to study DNA damage and to repair patterns in human cells $(17,18)$. For in vivo footprinting applications, LMPCR analysis requires the detection of breaks, or lesions convertible to breaks, at a frequency of approximately one in every 100 bases. By contrast, the requirement for DNA damage and repair studies is sensitivity to detect one break per kilobase $(7,9,27,31-33)$, which is achievable using an elaborate multi-day LMPCR protocol with radioactive detection. To date, LMPCR is the only method capable of detecting enhanced repair of the transcribed strand near the transcription start $(9,30)$. Sequence-specific interactions of DNA and drugs at nucleotidelevel resolution have been investigated (1-3) as well as damage or repair maps for oxidatively damaged bases (21-24) and methylated purines (33). Together, these studies have helped to illuminate the sequence-context-dependent nature of DNA repair in higher eukaryotes.

The p53 gene, which codes for a tumor suppressor gene mutated in a majority of human cancers, is among the few genes that have been well studied by LMPCR. DNA damage and repair have been linked to mutations in the p53 gene in human tumors by comparing cyclobutane pyrimidine dimer (CPD) formation and repair in the p53 gene to the tumor database of p53 mutations in skin cancer $(8,25,27)$. Hot- spots for mutation in skin tumors were correlated with slow spots for the repair of damage due to electromagnetic spectrum from 280 to $320 \mathrm{~nm}$ (UVB). In human bronchial epithelial cells, a molecular link was established between the patterns of damage and repair of the benzo[a]pyrene 7,8-diol 9,10-epoxide (BPDE) adducts formed in the p53 gene and the patterns of p53 mutations observed in lung tumors of smokers $(6,7)$.

To obtain the necessary sensitivity, most studies of DNA damage and repair have required the transfer of separated DNA fragments to a membrane, followed by hybridization with ${ }^{32} \mathrm{P}-\mathrm{la}-$ beled probes $(16,18)$. Including the membrane transfer step, LMPCR usually required four to five days. Recently, Dai et al. (4) established that robotic liquid handling for most steps of LMPCR, combined with near-infrared fluorescent detection, can improve in vivo footprinting. We also describe additional details of the one-day method, compare non-robotic with robotic procedures, and report simultaneous analysis of multiple sequences. Here we describe protocol modifications that increase sensitivity and make robotic LMPCR suitable for the high-throughput study of DNA damage and repair as well as in vivo footprinting and chromatin fine-structure analysis (12).

\section{MATERIALS AND METHODS}

Cell Lines, UV Irradiation, DNA Purification, and Enzymatic Cleavage

HeLa cell DNA was used as a template for Maxam-Gilbert chemical sequencing reactions (13) and for dimethyl 
Table 1. Synthetic Oligomer Primers for LMPCR Analysis of p53 Exons 5-8

\begin{tabular}{|c|c|c|c|c|c|c|}
\hline & & & & & $\mathbf{T}_{\mathbf{m}}$ & \\
\hline Prime & er Sequence & length & $+C(\%$ & ospX & OLIGO & Primer3 \\
\hline & For lower strand (transcribed strand, $5^{\prime} \rightarrow 3^{\prime}$ ) & & & & & \\
\hline $5-1^{*}:$ & CACTTGTGCCСTGACTTTCAAC & 22 & 50 & 60.1 & 57.4 & 62.0 \\
\hline $5-2^{*}:$ & TGСССТGАСТTTСААСТСТGTСТСС & 25 & 52 & 63.6 & 61.0 & 67.1 \\
\hline 5-3: & GCCCTGACTTTCAАCTCTGTCTCСTTCC & 28 & 53 & 66.4 & 63.8 & 70.0 \\
\hline 6-1: & AGACGACAGGGCTGGTTG & 18 & 61 & 59.6 & 56.9 & 59.8 \\
\hline 6-2: & GGGCTGGTTGCCCAGGGT & 18 & 72 & 64.1 & 61.5 & 67.9 \\
\hline $6-3^{*}:$ & GTCCCCAGGCCTCTGATTCCTC & 22 & 63 & 65.7 & 63.0 & 67.6 \\
\hline 7-1: & CTGCTTGCCACAGGTCTC & 18 & 61 & 59.6 & 56.9 & 58.0 \\
\hline 7-2: & ACAGGTCTCCCCAAGGCGCA & 20 & 65 & 64.0 & 61.3 & 69.7 \\
\hline 7-3: & GCACTGGCCTCATCTTGGGCCT & 22 & 63 & 65.7 & 63.0 & 70.9 \\
\hline 8-1: & GGGACAGGTAGGACCTGATTT & 21 & 52 & 60.0 & 57.3 & 59.3 \\
\hline 8-2: & GACCTGATTTCCTTACTGCСTCTTGСTT & 28 & 46 & 63.5 & 60.8 & 67.6 \\
\hline & CTGCСTCTTGСTTCTCTTTTCСTATCCTGA & G 31 & 48 & 66.0 & 63.4 & 70.3 \\
\hline For up & pper strand (non-transcribed strand, $5^{\prime} \rightarrow 3^{\prime}$ ) & & & & & \\
\hline 5-4: & TGGGGACCCTGGGCAA & 16 & 68 & 59.2 & 56.6 & 64.7 \\
\hline 5-5: & GCAACCAGCCСTGTCGTCTC & 20 & 65 & 64.0 & 61.3 & 65.6 \\
\hline $5-6^{*}:$ & TCTCTCCAGCCCCAGCTGCTCAC & 23 & 65 & 67.3 & 64.6 & 71.5 \\
\hline 6-4: & AGGGCCACTGACAACCAC & 18 & 61 & 59.6 & 56.9 & 59.5 \\
\hline 6-5: & ACTGACAACCACССТTAACСССТС & 24 & 54 & 63.7 & 61.0 & 65.6 \\
\hline 6-6: & TAACСССТССТСCCAGAGACCC & 22 & 63 & 65.7 & 63.0 & 66.8 \\
\hline 7-4: & GCAAGCAGAGGCTGGG & 16 & 68 & 59.2 & 56.6 & 60.0 \\
\hline 7-5: & TGGGGCACAGCAGGCCAGT & 19 & 68 & 64.0 & 61.4 & 65.6 \\
\hline 7-6*: & CACAGCAGGCCAGTGTGCAGGGT & 23 & 65 & 67.3 & 64.6 & 73.0 \\
\hline 8-4: & CTGAGGCATAACTGCACCCTT & 21 & 52 & 60.0 & 57.3 & 61.6 \\
\hline 8-5: & GCATAACTGCACCCTTGGTCTCCT & 24 & 54 & 63.7 & 61.0 & 66.8 \\
\hline 8-6: & TTGGTCTCCTCCACCGCTTCTTGTCCTG & 28 & 57 & 67.9 & 65.2 & 75.0 \\
\hline $\begin{array}{l}\text { Each } \\
\text { nential } \\
\text { mal cy } \\
\text { rect lal } \\
\text { are dis } \\
\text { marke }\end{array}$ & $\begin{array}{l}\text { set consists of an oligonucleotide suitable for } \mathrm{p} \\
\text { al PCR (-2, }-5 \text {, or } \mathrm{P} 2) \text {, and labeled with dyes for } \\
\text { ycler was set for } 60^{\circ} \mathrm{C}, 64^{\circ} \mathrm{C}, 66^{\circ} \mathrm{C} \text { for the prime } \\
\text { abeling stages, respectively. The results from os } \\
\text { isplayed. Primers were originally designed usin } \\
\text { ed with asterisks, which were described previou }\end{array}$ & $\begin{array}{l}\text { rimer } \\
\text { direct } \\
\text { er exte } \\
\text { spX, O } \\
\text { ig the c } \\
\text { usly (2 }\end{array}$ & $\begin{array}{l}\text { ensior } \\
\text { beling } \\
\text { ion, ex } \\
\text { GO ve } \\
\text { X pros }\end{array}$ & $\begin{array}{l}(-1,-4 \\
(-3,-6, \\
\text { ponent } \\
\text { sion } 5 \\
\text { ram, e) }\end{array}$ & $\begin{array}{l}\text { or P1) } \\
\text { or P3). } \\
\text { al PCF } \\
\text {, and } \\
\text { ceept fc }\end{array}$ & $\begin{array}{l}\text { expo- } \\
\text { he ther- } \\
\text { and di- } \\
\text { imer3 } \\
\text { primers }\end{array}$ \\
\hline
\end{tabular}

sulfate followed by $E$. coli 3-methyladenine-DNA glycosylase II (DMS/AlkA) treatments (33). Human skin fibroblast cells were used for bacteriophage T4 UV endonuclease $\mathrm{V}$ and E. coli DNA photolyase-treated samples (18). Fibroblasts were grown to confluent monolayers and irradiated in Petri dishes with five doses (700, 900, 1100, 1300, and $1500 \mathrm{~J} / \mathrm{m}^{2}$ ) of UVB. For studies of the time course of DNA repair, the cells were irradiated by electromagnetic spectrum from 200 to $280 \mathrm{~nm}$ (UVC) from a germicidal lamp at a dose of $20 \mathrm{~J} / \mathrm{m}^{2}$ at $254 \mathrm{~nm}$. After UV irradiation or repair, the nuclei were isolated, and the DNA was purified as previously described (28).

For the detection of CPD damage caused by UVB light, DNA samples were first cleaved with T4 UV endonuclease $\mathrm{V}$, and the dimers were photoreactived using DNA photolyase $(9,26$, 27). N-methylpurines generated by DMS were revealed as DNA breaks using the E. coli AlkA protein, followed by incubation in $1 \mathrm{M}$ piperidine (33).
Nested Oligonucleotide Primers for LMPCR of Exons 5-9 of the Human p53 Gene

LMPCR primers were designed in sets of three, with the first primer (P1 or $\mathrm{P} 4)$ for the extension step, the second (P2 or P5) for exponential PCR, and the third (P3 or P6) for direct labeling reactions. $\mathrm{P} 3$ or $\mathrm{P} 6$ primers were $5^{\prime}$-labeled during chemical synthesis using the near-infrared dyes IRDye $\mathrm{T}^{\mathrm{TM}} 700$ or 800 (LI-COR, Lincoln, NE, USA). The manufacturer generally performed the syntheses of P3 or P6. The primers for revealing the transcribed strand were designated P1, P2, and P3; the primers for the non-transcribed strand were $\mathrm{P} 4$, P5, and P6. This nomenclature was further extended so that primers 5-1 and 54 are, respectively, the $\mathrm{P} 1$ and $\mathrm{P} 4$ primers for exon 5. Parameters important for LMPCR were first investigated using primers designed previously for analysis of the non-transcribed strand of exon 5 , but using the $\mathrm{T}_{\mathrm{m}}$ values defined by the ospX program (29). These p53 exon 5 primers were:

\section{$5-4, \mathrm{~T}_{\mathrm{m}}=62^{\circ} \mathrm{C}$ by ospX $\left[54^{\circ} \mathrm{C} ;(27)\right]$, GGCAACCAGCCCTGTCG}

$5-5, \mathrm{~T}_{\mathrm{m}}=69^{\circ} \mathrm{C}$ by ospX $\left[65^{\circ} \mathrm{C} ;(27)\right]$, CCAGCCCTGTCGTCTCTCCAGCC $5-6, \mathrm{~T}_{\mathrm{m}}=67^{\circ} \mathrm{C}$ by ospX $\left[64^{\circ} \mathrm{C} ;(27)\right]$, TCTCTCCAGCCCCAGCTGCTCAC

To enable all primers to hybridize under the same thermal cycling conditions and to allow for multiplexing of more than one primer set in the primer extension reaction, we designed new primer sets. Eight primer sets for p53 exons, each set with progressively increasing $\mathrm{T}_{\mathrm{m}}$ values were designed using the ospX program with default parameters (10). Table 1 displays these new primer sets for exons 5-8. For comparative purposes, $\mathrm{T}_{\mathrm{m}}$ values calculated by the OLIGO ${ }^{\mathrm{TM}}$ version 5.1 software (National Biosciences, Plymouth, MN, USA) (5) and Primer3 (http://www-genome.wi.mit.edu/cgi-bin/ primer/primer3_www.cgi) also are listed in Table 1. The $\mathrm{T}_{\mathrm{m}}$ values obtained using ospX and OLIGO version 5.1 are similar, with a consistent offset, but the Primer3 values were inconsistent with the other values obtained. 


\section{Robotic Hot-Start LMPCR}

Robotic LMPCR, which consists of three cascading stages of AmpliGrease (11), was carried out on a Biomek ${ }^{\circledR}$ 2000 workstation (Beckman Coulter, Fullerton, CA, USA) as previously described (4) unless otherwise stated. For example, the dNTP concentration was changed to $800 \mu \mathrm{M}$ for the primer extension step when processing UV-treated and DMS/AlkA-treated DNA. The compositions of the premixtures are presented in Figure 1 and in the Results section for both single and duplex primer reactions. All premixtures, calculated by multiplying the number of reactions times per the reaction volumes displayed in Figure 1, were prepared manually on ice and transferred to the workstation for liquid handling steps. Primer extension, ligation, exponential PCR, and direct labeling reactions were set up in PCR tube strips in a tube strip holder (both from Stratagene, La Jolla, CA, USA) cemented to a Biomek Labware holder. BioWorks ${ }^{\circledR} 3.1$ and BioScript Pro ${ }^{\circledR}$ software packages (both from Beckman Coulter) were used to set up the Biomek 2000 workstation. To accommodate the PCR tube holder, the device definition for PCR plates was copied (under the Edit Device menu), and the definition was modified to conform to the added height of the PCR tube rack. Pipetting of the bottom and top premixtures was accomplished using 50- $\mu \mathrm{L}$ tips (Robbins Scientific, Sunnyvale, CA, USA), and the Biomek P20 tool with the BioWorks software was set for a pipetting speed of eight. For bottom premixtures, the BioWorks software was set to deliver the sample while positioned at a height equal to $6.5 \%$ of the tube height or 1.37 $\mathrm{mm}$ from the tube bottom. After pipetting the bottom premixture, DNA (0.5-1 $\mu \mathrm{g} / \mu \mathrm{L}$ ) was added manually. Mineral oil $(7.5 \mu \mathrm{L})$ was aspirated at a speed of 7 and dispensed at a height of $20 \%$ at a speed setting of 6 using the Biomek MP200 tool and P250 tips (Beckman Coulter). Molten petroleum jelly (approximately $20 \mu \mathrm{L}$ ) was pipetted using a program written in the BioScript Pro version of the tool command language (TCL). To increase the reliability of dispensing the molten petroleum jelly, P250 tips were preheated using a hot-air blower and additionally heated by multi- ple aspiration and dispensing steps using the Biomek MP200 tool. Following those steps, the molten petroleum jelly was dispensed into PCR tubes. Mineral oil $(142 \mu \mathrm{L})$ was then added at a height of $75 \%$ with the same tips, tool, and speeds as before. Top premixture [containing PfuTurbo ${ }^{\circledR}$ DNA polymerase (Stratagene)] was aspirated at a speed of 4 and dispensed at a height of $50 \%$ at a speed setting of 5. Cap strips (Stratagene) were put in place before the thermal cycling. Cycle conditions, displayed in Figure 1, were carried out in a TwinBlock $^{\mathrm{TM}}$ Easy Cycler ${ }^{\mathrm{TM}}$ unit (Ericomp, San Diego, CA, USA). For procedures in later stages in the LMPCR process, similar BioWorks procedures were used. These programs are available on request.

\section{Non-Robotic LMPCR}

The starting point for the robotic protocol with fluorescent detection was a non-robotic two-day procedure (16). A modified version of this procedure was used for comparison with the robotic procedure. In brief, PfuTurbo DNA polymerase was used in both primer extension and PCR. For primer extension, $1 \mu \mathrm{L}$ DNA $(0.4-1 \mu \mathrm{g})$ was added to $4 \mu \mathrm{L}$ premixture that con-

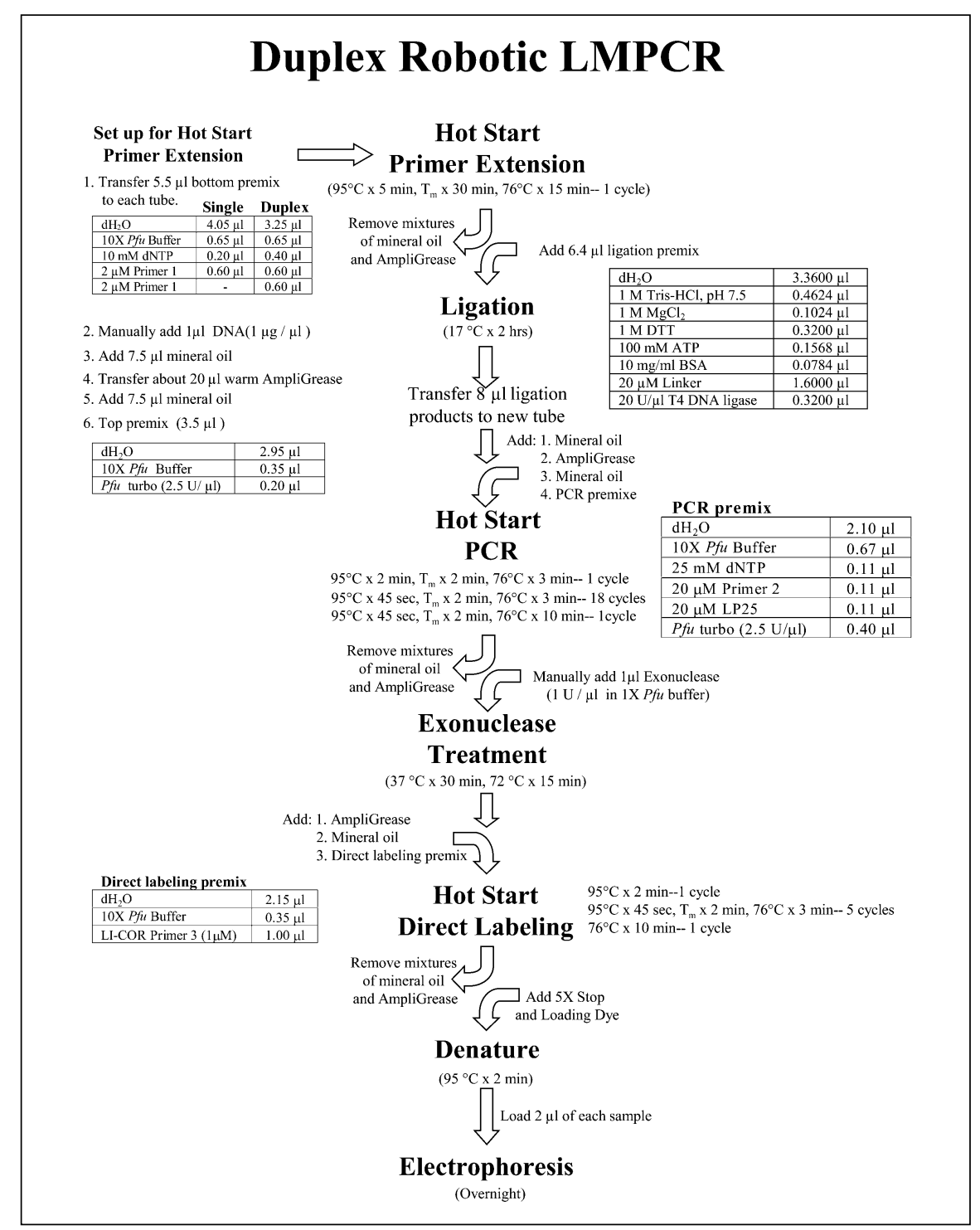

Figure 1. Outline of the robotic LMPCR procedure. Premixes for single and duplex primer reactions are displayed. This protocol is optimized for samples with damage frequencies greater than 1 break per kb. One major change for low damage frequency samples is the use of $800 \mu \mathrm{M}$ dNTP for the primer extension reaction. The column labeled Duplex indicates experiments with two primers in one reaction. 
tained $0.5 \mu \mathrm{L} 10 \times$ PfuTurbo DNA polymerase buffer, $0.5 \mu \mathrm{L} 2.5 \mathrm{mM}$ dNTP, $0.3 \mu \mathrm{L} 2 \mu \mathrm{M}$ primer $1,0.5 \mu \mathrm{L}$ PfuTurbo DNA polymerase $(2.5 \mathrm{U} / \mu \mathrm{L})$, and $2.2 \mu \mathrm{L}$ water. The ligation premixture composition was identical to that earlier described (16). The 8- $\mu \mathrm{L}$ PCR premixture contained $2 \mu \mathrm{L} 10 \times$ PfuTurbo

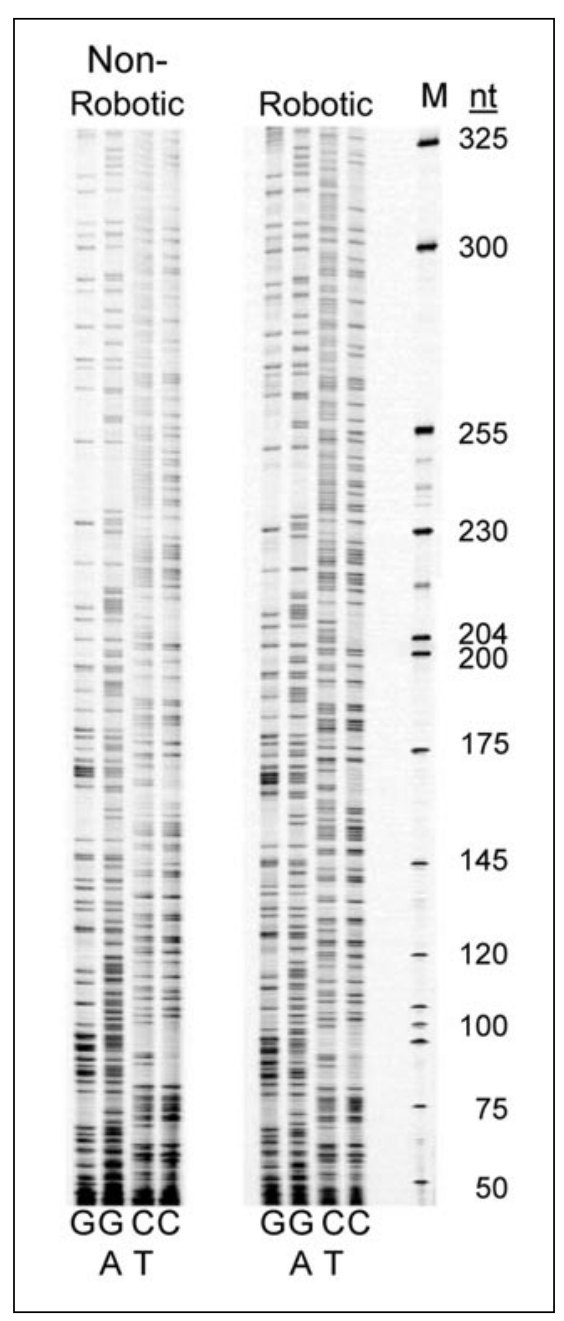

Figure 2. Comparison of non-robotic and robotic hot start LMPCR for the non-transcribed strand of exon 5 of the human p53 gene. For these experiments, primers 5-4 and 5-5 [listed in Materials and Methods and previously described (29)] were used in combination with primer 5-6 (Table 1). The lane marked $M$ was loaded with IRDye700 50-350 Sizing Standard. Lanes labeled $\mathrm{G}, \mathrm{GA}, \mathrm{CT}$, and $\mathrm{C}$ contain the products of Maxam-Gilbert $\mathrm{G}, \mathrm{G}+\mathrm{A}, \mathrm{C}+\mathrm{T}$, and $\mathrm{C}$ sequencing reactions. One microgram of HeLa DNA was used per reaction. (A) Non-robotic LMPCR, as described in the Materials and Methods section. Solutions for the reactions were maintained on ice until just before initiation. (B) Robotic hot start LMPCR, as described in the Materials and Methods section. Solutions for the reactions were maintained at room temperature on the Biomek 2000 work surface. nt, nucleotide length.
DNA polymerase buffer, $0.2 \mu \mathrm{L} 25 \mathrm{mM}$ dNTP, $0.2 \mu \mathrm{L} 20 \mu \mathrm{M}$ primer $2,0.2 \mu \mathrm{L}$ $20 \mu \mathrm{M}$ LP25 (sequence in Reference 16), $0.8 \mu \mathrm{L}$ PfuTurbo DNA polymerase $(2.5 \mathrm{U} / \mu \mathrm{L})$, and $4.6 \mu \mathrm{L}$ water. One microliter of IRDye-labeled primer 3 was added directly to $10 \mu \mathrm{L}$ PCR products with or without exonuclease I treatment after PCR. All the conditions used for the thermal cycler reactions for primer extension, PCR, exonuclease treatment, and direct labeling are the same as for the robotic protocol.

\section{RESULTS AND DISCUSSION}

\section{Comparison of Non-Robotic and Robotic One-Day Procedure with Fluorescent Detection}

Access to robotic liquid handling workstations remains limited in most laboratories; on the other hand, ABI Prism ${ }^{\circledR}$ automated sequencing equipment (Applied Bioystems, Foster City, CA, USA) is widely disseminated. Our attempts to use oligonucleotide primers fluorescencing in visible wavelengths synthesized by and analyzed using slab gel ABI Prism instruments provided results that displayed higher background compared to the LI-COR near-infrared dyes and dye instruments; hence, these were not further evaluated. Figure 2 displays the results acquired using robotic and non-robotic versions of the short LMPCR protocol. Using the LICOR dyes and instrumentation, comparable results are obtained either manually or by use of a Biomek 2000 robotic workstation for liquid handling steps. More than 300 nucleotides can be visualized in one sequencing gel, and the bands are sharp and well separated; this application of LMPCR to sequencing is limited to some extent by the side reactions inherent to Maxam-Gilbert chemistry. Thus, Maxam-Gilbert resequencing is displayed primarily to delineate the positions of the breaks in DNA damage. The data as collected are digitized so that software programs such as RFLPScan $^{\mathrm{TM}}$ (Scanalytics, Fairfax, VA, USA) can be used for lane identification and scans (see Figure 5B). The LICOR data are superior both in quality and read length to standard methods using ${ }^{32} \mathrm{P}$ that usually give good quality 
data with complete separation of bands only over 100-150 nucleotides. The robotic method produces an LMPCR signal that is more intense than the non-robotic procedure, which we attribute to the use of AmpliGrease hot start. If a LI-COR instrument is not available, then ${ }^{32} \mathrm{P}$-labeled or ${ }^{33} \mathrm{P}$-labeled primers can, of course, be substituted for the fluorescence-labeled primers.

There are several advantages to using the robotic protocol for LMPCR. (i) The hot-start procedure in the robotic protocol reduces the chance of nonspecific priming and primer degradation by DNA polymerases during the processing of samples at a robotic workstation since these solutions are maintained at room temperature between reactions. It also allows primer extension, PCR, or direct labeling to begin at the same time regardless of how many samples are analyzed. (ii) The nonradioactive detection eliminates problems that arise in manipulation of radioactive materials. (iii) The reproducibility of a robotic performance on the robotic workstation reduces the variation between samples that is important when numerous experiments are performed.

\section{Investigation of Critical Parameters for LMPCR at High Damage Frequency}

LMPCR protocols have numerous steps, all of which ultimately should be optimized. In brief, these steps include: DNA preparation, primer extension, linker ligation, PCR, DNA fragment separation, and detection. Figure 1 outlines the protocol developed and used for many of the robotic procedures described here. In several previous studies, Vent ${ }^{\circledR}$ (exo-/-) DNA polymerase (New England Biolabs, Beverly, MA, USA) was used. However, it was discovered that the results obtained sometimes depended on the lot of the Vent DNA polymerase. This variability is more serious at the low-nick frequencies needed for the study of DNA repair. Similar variability with Vent has been reported by others. Therefore, we compared PfuTurbo DNA polymerase and Vent (exo-/-) DNA polymerase in the primer extension and PCR steps and then with the two steps combined. Where Vent (exo-/-) DNA polymerase is used in both the primer extension and PCR steps, a relatively weak LMPCR signal was produced (data not shown). Although we found that the use of $P f u$ Turbo DNA polymerase is critical, in the primer extension step, we routinely use PfuTurbo for both primer extension and PCR steps.

Previous work has shown that ligation is substantially complete after 45 $\min$ at $15^{\circ} \mathrm{C}(14)$. However, LMPCR

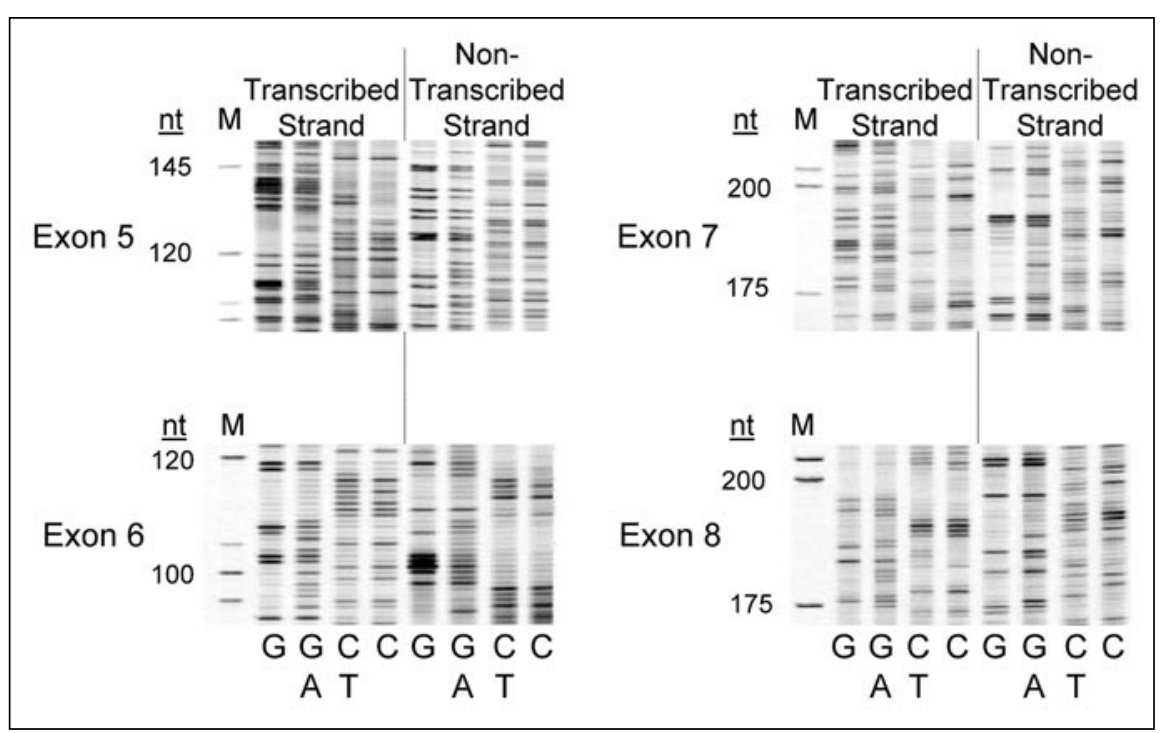

Figure 3. Robotic LMPCR with various primer sets for exons 5-8 of the human p53 gene. Lanes 1-4 represent Maxam-Gilbert sequencing reactions G, GA, CT, and C. The robotic protocol described in Figure 1 and the Materials and Methods section was used. The primer sets used are given in Table 1. See Figure 2 legend for molecular weight standards (M).

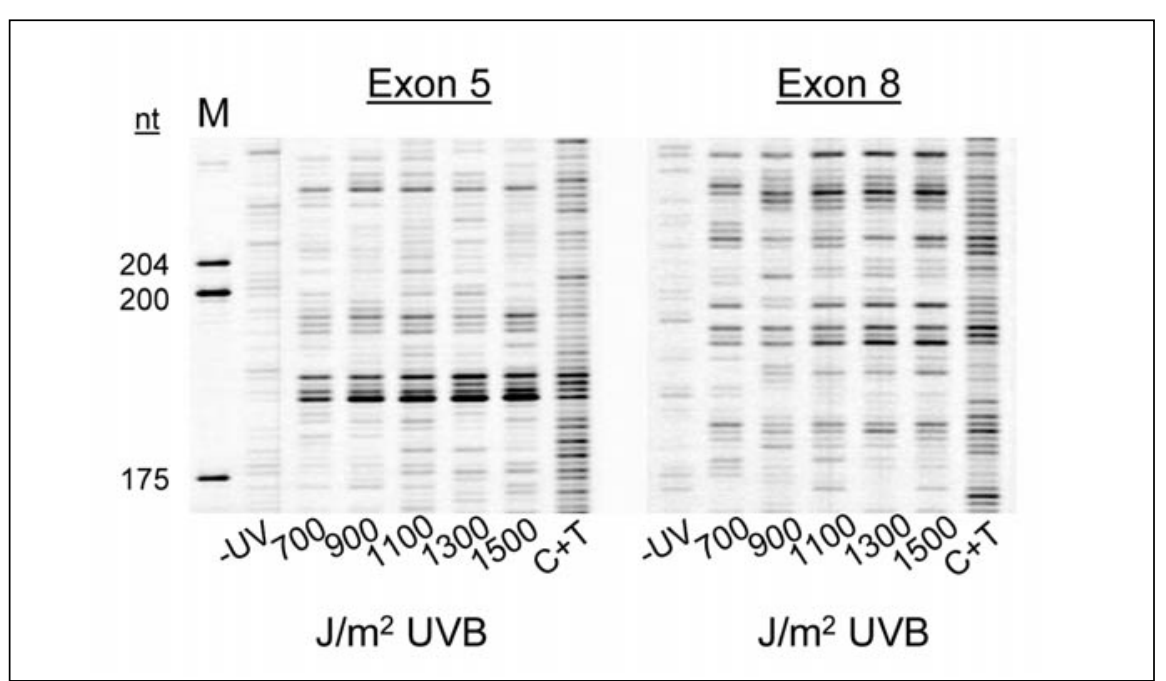

Figure 4. Duplex primer extension and ligation. Primers for the transcribed strand of exon 5 and exon 8 of the human p53 gene were present in the same reaction. DNA $(0.5 \mu \mathrm{g})$ isolated from UVB-treated $\left(700-1500 \mathrm{~J} / \mathrm{m}^{2}\right.$ ) human skin fibroblasts (approximately 1 break/6 kb) was used in each tube. After ligation, the reaction was divided into two aliquots, and the exponential PCR and direct labeling were performed separately with primers 2 and 3 (Table 1 ) for the relevant exon strands (5-2 and 5-3 for exon 5; 82 and 8-3 for exon 8). See Figure 2 legend for molecular weight standards (M). 
be completed in one day.

The gene-specific primers for the exons used to begin this study and in our earlier study (4) were designed for con- ventional LMPCR (29). The direct labeling primers (e.g., primer 3 in Figure 1) had the same or even lower $T_{m}$ than the PCR primers. In addition, the PCR

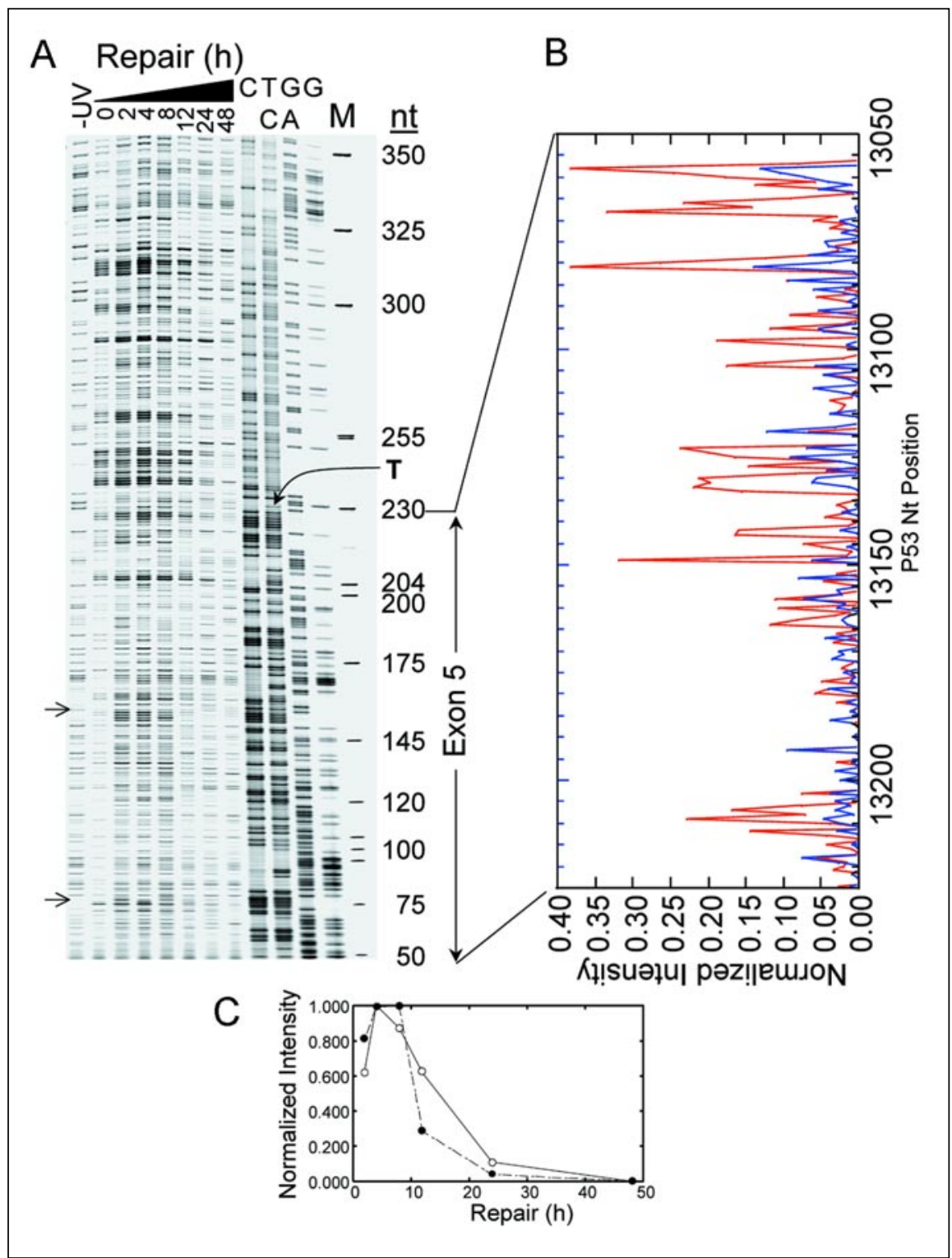

Figure 5. Repair of UVC-induced CPD along exon 5 and flanking intron sequences of the human p53 gene. One microgram of $20 \mathrm{~J} / \mathrm{m}^{2}$ UVC-treated human skin fibroblast DNA (about 1 break $/ 5 \mathrm{~kb}$ ) was used in each reaction. See Figure 2 legend for molecular weight standards (M). (A) Autoradiogram-like representation of the fluorescent data for the LMPCR experiment. The repair time for each lane is indicated. Lanes labeled G, GA, CT and C contain the products of Maxam-Gilbert sequencing reaction performed on HeLa cell DNA. M indicates the marker lane, nt corresponds to the size of the marker band, $\mathrm{T}$ represents the first nucleotide in exon 5, and the arrows indicate the bands whose intensities, estimated by Gaussian deconvolution, are displayed in panel C. (B) Relative-intensity scans using the RFLPScan for the 2-h (red trace) and 48-h samples (purple trace). Gaussian deconvolution to resolve all bands was performed after automatic baseline correction and background subtraction using RFLPScan software from the image displayed in panel A. (C) Repair of CPD of the bands at the mutation hotspots found in codons $155(-)$ ) and $177(\bigcirc-\bigcirc)$ of the human p53 gene. Bands intensities calculated by Gaussian deconvolution were normalized to the most intense band in the time series (the bands at a specific position from 0 to $48 \mathrm{~h}$ repair) compared to the lowest intensity band in the series. The Normalized Intensity $=\left(\mathrm{I}_{\mathrm{i}^{-}}\right.$ $\left.I_{\min }\right) /\left(I_{\max }-I_{\min }\right)$, where $I_{i}$ is the intensity of a given band, $I_{\max }$ is the highest intensity band in the series, and $\mathrm{I}_{\min }$ is the lowest intensity band in the series. primers ( $\mathrm{P} 2$ or $\mathrm{P} 4)$ are in excess following PCR and will compete to varying degrees with the direct labeling process. The PCR primers can be conveniently removed by treatment with $E$. coli exonuclease I before direct labeling (data not shown). If the direct-labeling primer (P3 or P6) has a considerably higher $\mathrm{T}_{\mathrm{m}}$ than the $\mathrm{PCR}$ primer $(\mathrm{P} 2$ or $\mathrm{P} 4)$, then exonuclease treatment may not be needed, but the use of exonuclease I affords significantly greater flexibility in the choice of labeling primers.

\section{Design of Primer Sets for Robotic Hot-Start LMPCR}

For our study of damage and repair in the 153 gene, we focused on stretches of the gene containing the majority of mutations listed in the human tumor database. Thus, we designed primer sets for exons 5-8 of the human p53 exons with $\mathrm{T}_{\mathrm{m}}$ values for primer extension, exponential $\mathrm{PCR}$, and direct labeling at $60^{\circ} \mathrm{C}, 64^{\circ} \mathrm{C}$, and $66^{\circ} \mathrm{C}$, respectively. Table 1 shows eight primer sets that we have used for analyzing p53 exons; the sets were designed using the primer selection program ospX. Calculated $\mathrm{T}_{\mathrm{m}} \mathrm{s}$ are shown along with those obtained with OLIGO version 5.1 and Primer3. The primers designed for exon 9 are not listed in Table 1 because the reactions that included those primers produced erratic results; there seems to be a sequence in exon 9 that stops primer extension and/or PCR. Both ospX and OLIGO version 5.1 designed primers that produced LMPCR results superior to those obtained using oligodeoxyribonucleotides designed by Primer3.

Figure 3 shows genomic sequencing results for p53 exons 5-8, all performed using the protocol in Figure 1, with identical thermal cycling conditions. Thus, LMPCR can be completed simultaneously for p53 exons 5-8 that harbor the most frequently mutated exons and that have been the focus of many DNA damage and repair studies.

\section{Genomic DNA and dNTP Concentrations in the Primer Extension Step}

Preliminary experiments established that DNA damage signals were relatively weak, using the same conditions 
that yielded strong signals for the Maxam-Gilbert sequencing standards (200 $\mu \mathrm{M}$ dNTP; $120 \mathrm{nM}$ Primer 1). Therefore, we retested several parameters using DNA irradiated with UVC so that there was an average of one CPD per 5 $\mathrm{kb}$. In experiments where two primer concentrations (60 and $120 \mathrm{nM}$ ) were examined over four dNTP concentrations $(200,800,1400$, and $2000 \mu \mathrm{M})$, we found that the dNTP concentration in the primer extension step was a critical factor. The use of $800 \mu \mathrm{M}$ dNTP in the primer extension reaction results in a strong LMPCR signal. Similar results were observed for the non-transcribed strand of exon 7 and the transcribed strand of exon 5 (data not shown). It was also determined that lower amounts of genomic DNA could be used for the LMPCR ( 0.4 as opposed to $1 \mu \mathrm{g}$; data not shown). Overall, the concentration of genomic DNA and the dNTP concentrations were found to be the most critical parameters in performing LMPCR, with other factors being less sensitive to alterations. The use of lower concentrations of genomic DNA is a distinct advantage that permits the conservation of DNA.

\section{Duplex Robotic Hot-Start LMPCR}

If there is no interference among primer sets for different genes or exons, then mutiple LMPCRs could be carried out in the same tube. In addition to the robotic LMPCR protocol, Figure 1 outlines the protocol for performing two primer extension and ligation steps in one tube. As an example, the primer extension and ligation reactions for the transcribed strand of p53 exons 5 and 8 were performed in a single tube. The subsequent reactions for each exon, $\mathrm{PCR}$, and direct labeling were performed in separate tubes. Figure 4 shows the results for such duplexed primer extension reactions for UVBdamaged DNA on the transcribed strand of exons 5 and 8 of the human p53 gene at different UVB fluxes. T4 UV endonuclease and photolyase reactions were used to convert CPD lesions into strand breaks detectable by LMPCR. The duplexing technique is also compatible with primers for non-transcribed strands of the same exons. In other experiments (data not shown), we have demonstrated that it is possible to combine all four first primer oligodeoxyribonucleotides for the non-transcribed p53 exons 5-8 and perform the primer extension and ligation steps in a single reaction tube. The multiplex primer extension and ligation steps should be evaluated for any study that will involve the use of several targets or repetitive analysis.

\section{Reproducibility and Response Linearity}

Another major reason to use the robotic technique is the precision of the reactions. Although there is evidence that LMPCR can detect the 2-fold differences for X-linked genes between the target gene concentration in male and female cells (20), data on the reproducibility of band intensities have not been published. The reproducibility of the individual reactions is greatly improved over the original LMPCR method $(9,27)$. Analysis of the same UV-treated DNA sample was performed in quadruplicate with liquid handling steps performed by the robotic workstation. The lane scans for each lane from 293 to -54 nucleotides of the human PGK-1 promoter region were fitted to Gaussian curves, and the area of each band was quantified using RFLPScan software. For bands of significant intensity (intensity $>0.15$ ), it was observed that the coefficients of variation were approximately $10 \%$. Only for the weakest bands (intensity $<0.02$ ) did the intensity vary more than 2 -fold.

If the data accumulated for the repair were not linear, then allowances would have to be made in the calculation of such differences. To confirm that band intensity was a linear function of DNA damage, we performed a dilution experiment using HeLa DNA treated with DMS at a low concentration (33). The $5^{\prime}$ phosphoryl groups necessary for LMPCR were generated at the alkylated sites using the AlkA enzyme, followed by a mild piperidine treatment that produced one break per $2 \mathrm{~kb}$. The total intensity of the $1-\mu \mathrm{g}$ lane was summed using RFLPScan software and assigned a value of 100 . The intensity of each of the individual bands was compared to this total intensity. The dilutions of the initial damaged DNA approximated a linear regression $\left(\mathrm{R}^{2} \geq\right.$
0.98), thus confirming that the sensitivity and linearity were sufficient for a quantitative assay of DNA repair or other studies of chromatin in vivo. These results are critical to the use of this technique because the use of visible sequencing dye systems or photographic methods of detection could generate data that are not linear and therefore not useful in the quantitative description of repair phenomena.

\section{Repair of UVB Damage to DNA in Normal Human Fibroblasts}

Figure 5 shows a repair experiment for exon 5 of the p53 gene. Human skin fibroblasts were irradiated with $20 \mathrm{~J} / \mathrm{m}^{2}$ UVC, generating approximately one lesion per $\mathrm{kb}$, the cells were harvested, and DNA was isolated after various times of repair. Figure 5B shows the relative intensity scans of the 50-230 nucleotide region for the 2-h and 48-h repair times. Repair data calculated for the p53 codons 155 and 177 are shown in Figure 5C. The LMPCR results obtained for the damage and repair by UVC irradiation are consistent with those presented by older radioactive LMPCR protocols (27). Note that it is also possible to distinguish differences in repair rates at mutation hotspots on the non-transcribed strand of the human p53 gene. There is a slight difference in the time of the maximum DNA damage, but it is possible that the difference ( $4 \mathrm{~h}$ in the current study vs. $2 \mathrm{~h}$ in previous work) reflects individual variation. The accumulation of data using the original LMPCR protocols for the p53 gene would require three to four weeks to complete. Using the robotic technique permits the reactions to be completed in one day. The limiting factor thus becomes gel analysis. The use of the two different IRDyes, which can be run and separately detected in the same gel lane, could reduce the requirement for gels by one half.

\section{CONCLUSION}

Here we have described a robotic LMPCR method that results in considerable time saving in performing reactions on genomic DNA with low break frequencies. The lengthy multi-day pro- 
cedure precluded the use of LMPCR for clinical samples. This LMPCR protocol should allow clinical researchers access to a technique that was previously limited to the analysis of cell culture. Collectively, data presented in this report favor the use of LMPCR in both research and clinical laboratories to understand where damage occurs in DNA and how cells repair those insults.

\section{ACKNOWLEDGMENTS}

We thank Jin Zhou, Ning Ye Zhou, Agnes Juhasz for preparation of the DNA templates used in this work, and Steven E. Bates for cell culture. This work was supported by National Institutes of Health grant nos. PO11CA69449 (G.P.H.), RO1 CA87590-01 (T.R.O.), RO1 CA90819-01 (T.R.O.), RO1 GM50575 (A.D.R.), P30CA33572 (City of Hope National Medical Center, Comprehensive Cancer Center Grant), and the National Science Foundation PhosphorImager Core Grant no. BIR-9920534.

\section{REFERENCES}

1.Cairns, M.J. and V. Murray. 1996. Influence of chromatin structure on bleomycin-DNA interactions at base pair resolution in the human beta-globin gene cluster. Biochemistry 35:8753-8760.

2.Cairns, M.J. and V. Murray. 1998. Detection of protein-DNA interactions at beta-globin gene cluster in intact human cells utilizing hedamycin as DNA-damaging agent. DNA Cell Biol. 17:325-333.

3.Cairns, M.J. and V. Murray. 1998. The DNA sequence specificity of hedamycin damage determined by ligation- mediated PCR and linear amplification. Biochem. Mol. Biol. Int. 46:267-275.

4.Dai, S.M., H.H. Chen, C. Chang, A.D. Riggs, and S.D. Flanagan. 2000. Ligation-mediated PCR for quantitative in vivo footprinting. Nat. Biotechnol. 18:1108-1111.

5.Davies, N.P., L.C. Hardman, and V. Murray. 2000. The effect of chromatin structure on cisplatin damage in intact human cells. $\mathrm{Nu}$ cleic Acids Res. 28:2954-2958.

6.Denissenko, M.F., A. Pao, G.P. Pfeifer, and M. Tang. 1998. Slow repair of bulky DNA adducts along the nontranscribed strand of the human p53 gene may explain the strand bias of transversion mutations in cancers. Oncogene 16:1241-1247.

7.Denissenko, M.F., A. Pao, M. Tang, and G.P. Pfeifer. 1996. Preferential formation of benzo[a]pyrene adducts at lung cancer mutational hotspots in P53. Science 274:430-432.
8.Drouin, R. and J.P. Therrien. 1997. UVB-induced cyclobutane pyrimidine dimer frequency correlates with skin cancer mutational hotspots in p53. Photochem. Photobiol. 66:719-726.

9.Gao, S., R. Drouin, and G.P. Holmquist. 1994. DNA repair rates mapped along the human PGK1 gene at nucleotide resolution. Science 263:1438-1440.

10.Hillier, L. and P. Green. 1991. OSP: a computer program for choosing PCR and DNA sequencing primers. PCR Methods Appl. 1:124128.

11.Horton, R.M., B.L. Hoppe and B.M. ContiTronconi. 1994. AmpliGrease: "hot start" PCR using petroleum jelly. BioTechniques 16:42-43.

12.Kontaraki, J., H.H. Chen, A. Riggs, and C. Bonifer. 2000. Chromatin fine structure profiles for a developmentally regulated gene: reorganization of the lysozyme locus before trans-activator binding and gene expression. Genes Dev. 14:2106-2122.

13.Maxam, A.M. and W. Gilbert. 1980. Sequencing end-labeled DNA with base-specific chemical cleavages. Methods Enzymol. 65:499-560.

14.Mueller, P.R., P.A. Garrity, and B. Wold. 1992. Ligation-mediated PCR for genomic sequencing and footprinting, p. unit 15.15. In F.M. Ausubel, R. Brent, R.E. Kingston, D.D. Moore, J.G. Seidman, J.A. Smith and K. Struhl (Eds.), Current Protocols in Molecular Biology. J. Wiley and Sons, New York.

15.Mueller, P.R. and B. Wold. 1989. In vivo footprinting of a muscle specific enhancer by ligation mediated PCR. Science 246:780-786.

16.Pfeifer, G.P., H.H. Chen, J. Komura, and A.D. Riggs. 1999. Chromatin structure analysis by ligation-mediated and terminal transferase-mediated polymerase chain reaction. Methods Enzymol. 304:548-571.

17.Pfeifer, G.P., R. Drouin and G.P. Holmquist. 1993. Detection of DNA adducts at the DNA sequence level by ligation-mediated PCR. Mutat. Res. 288:39-46.

18.Pfeifer, G.P., R. Drouin, A.D. Riggs, and G.P. Holmquist. 1991. In vivo mapping of a DNA adduct at nucleotide resolution: detection of pyrimidine (6-4) pyrimidone photoproducts by ligation-mediated polymerase chain reaction. Proc. Natl. Acad. Sci. USA 88:1374-1378.

19.Pfeifer, G.P., S.D. Steigerwald, P.R. Mueller, B. Wold, and A.D. Riggs. 1989. Genomic sequencing and methylation analysis by ligation mediated PCR. Science 246:810-813.

20.Pfeifer, G.P., R.L. Tanguay, S.D. Steigerwald, and A.D. Riggs. 1990. In vivo footprint and methylation analysis by PCR-aided genomic sequencing: comparison of active and inactive $\mathrm{X}$ chromosomal DNA at the $\mathrm{CpG}$ island and promoter of human PGK-1. Genes Dev. 4:1277-1287.

21.Rodriguez, H. and S.A. Akman. 1998. Mapping oxidative DNA damage at nucleotide level. Free Radic. Res. 29:499-510.

22.Rodriguez, H. and S.A. Akman. 1999. Measurement of oxidative DNA damage in the human p53 and PGK1 gene at nucleotide resolution. Ann. NY Acad. Sci. 893:382-385.

23.Rodriguez, H., R. Drouin, G.P. Holmquist, and S.A. Akman. 1997. A hot spot for hydrogen peroxide-induced damage in the human hypoxia-inducible factor 1 binding site of the PGK 1 gene. Arch. Biochem. Biophys. 338:207-212.

24.Rodriguez, H., R. Drouin, G.P. Holmquist, T.R. O'Connor, S. Boiteux, J. Laval, J.H. Doroshow, and S.A. Akman. 1995. Mapping of copper/hydrogen peroxide-induced DNA damage at nucleotide resolution in human genomic DNA by ligation-mediated polymerase chain reaction. J. Biol. Chem. 270:1763317640.

25.Tommasi, S., M.F. Denissenko, and G.P. Pfeifer. 1997. Sunlight induces pyrimidine dimers preferentially at 5-methylcytosine bases. Cancer Res. 57:4727-4730.

26.Tormanen, V.T. and G.P. Pfeifer. 1992. Mapping of UV photoproducts within ras protooncogenes in UV-irradiated cells: correlation with mutations in human skin cancer. Oncogene 7:1729-1736.

27.Tornaletti, S. and G.P. Pfeifer. 1994. Slow repair of pyrimidine dimers at p53 mutation hotspots in skin cancer. Science 263:14361438 .

28.Tornaletti, S. and G.P. Pfeifer. 1995. UV light as a footprinting agent: modulation of UV-induced DNA damage by transcription factors bound at the promoters of three human genes. J. Mol. Biol. 249:714-728.

29.Tornaletti, S., D. Rozek, and G.P. Pfeifer. 1993. The distribution of UV photoproducts along the human p53 gene and its relation to mutations in skin cancer. Oncogene 8:20512057.

30.Tu, Y., S. Tornaletti, and G.P. Pfeifer. 1996. DNA repair domains within a human gene: selective repair of sequences near the transcription initiation site. EMBO J. 15:675-683.

31.Wei, D., V.M. Maher, and J.J. McCormick. 1995. Site-specific rates of excision repair of benzo[a]pyrene diol epoxide adducts in the hypoxanthine phosphoribosyltransferase gene of human fibroblasts: correlation with mutation spectra. Proc. Natl. Acad. Sci. USA 92:2204-2208.

32.Wei, D., V.M. Maher, and J.J. McCormick. 1996. Site-specific excision repair of 1-nitrosopyrene-induced DNA adducts at the nucleotide level in the HPRT gene of human fibroblasts: effect of adduct conformation on the pattern of site-specific repair. Mol. Cell Biol. 16:3714-3719.

33.Ye, N., G.P. Holmquist, and T.R. O'Connor. 1998. Heterogeneous repair of Nmethylpurines at the nucleotide level in normal human cells. J. Mol. Biol. 284:269-285.

Received 16 April 2002; accepted 4 September 2002.

Address correspondence to:

Dr. Steven D. Flanagan

Division of Neurosciences

Beckman Research Institute

City of Hope National Medical Center

1500 East Duarte Road

Duarte, CA 91010, USA

e-mail:sflan@coh.org 